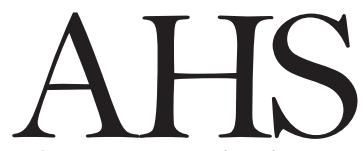

Advances in Horticultural Science

\title{
A new pneumatic harvester for improvement and facilitation the harvesting of the olive fruits
}

\author{
F. Zare ${ }^{1}$, G. Najafi ${ }^{1}(*)$, T. Tavakoli Hashjin ${ }^{1}$, A.M. Kermani ${ }^{2}$, P. Ghiasi ${ }^{1}$ \\ 1 Biosystems Engineering Department, Tarbiat Modares University \\ (TMU), Tehran, Iran. \\ 2 Department of Agro-Technology Engineering, College of Aburaihan, \\ University of Tehran, Tehran, Iran.
}

Key words: collector systems, harvesting damage, manual harvest, mechanical harvesting, olive tree.

OPEN ACCESS

${ }^{(*)}$ Corresponding author: g.najafi14@modares.ac.ir

Citation:

ZARE F., NAJAFI G., TAVAKOLI HASHJIN T., KERMANI A., GHIASI P., 2021 - A new pneumatic harvester for improvement and facilitation the harvesting of the olive fruits. - Adv. Hort. Sci., 35(1): 43-51

\section{Copyright:}

(C) 2021 Zare F., Najafi G., Tavakoli Hashjin T., Kermani A., Ghiasi P. This is an open access, peer reviewed article published by Firenze University Press (http://www.fupress.net/index.php/ahs/) and distributed under the terms of the Creative Commons Attribution License, which permits unrestricted use, distribution, and reproduction in any medium, provided the original author and source are credited.

Data Availability Statement:

All relevant data are within the paper and its Supporting Information files.

Competing Interests:

The authors declare no competing interests.

Received for publication 14 July 2020 Accepted for publication 27 January 2021
Abtract: The objective of this study was to measure and evaluate the performance of a New Pneumatic Harvester (NPH) for harvesting the olives fruit and compare the results with those of similar cases. The study involves two sections, namely, the NPH and the collector system. Two oily types of olive ('Mari' and 'Yellow') were selected to evaluate the NPH and the collector system. The randomized complete block design and Duncan's multi-scope test were used for variance analysis and means comparison purposes, respectively. The dependent parameters used to evaluate the NPH were harvesting productivity, harvesting efficiency, and leave downfall percent. Also, the fruit damage was selected for the collector system. Results showed that the NPH can harvest $92 \%$ of olive fruits. The highest amount of harvesting productivity belongs to NPH of $29.47 \mathrm{~kg} / \mathrm{h}$. The percent of leaves downfall in the harvesting process was found to be $2.55 \%$. Using the collector system can reduce the level of damaged fruit from $\mathbf{6 0 . 8 \%}$ to $25.12 \%$ and from $60.54 \%$ to $24.54 \%$ in the Mari and Yellow variety.

\section{Introduction}

The olive tree is one of the Mediterranean plants that its fruits used as a cannery and oil extraction (Barbera et al., 2013). Olive has traditionally been known among people, which is also important for health and used as a strategic food in some countries (Fiorino et al., 2010).

One of the major problems with the olive plant is harvesting which is mostly done in different ways: (a) picking up the fruit on the ground (b) harvesting manually (c) harvesting via branch shaker (d) harvesting mechanically (Lupi et al., 2012). Harvesting is the final step in field production of olive fruits, but if done at the wrong time or in the wrong way it can markedly affect the grower's net return. The economic success of super-intensive olive plantations is mainly achieved due to the full mechanization of harvesting (Ottanelli et al., 2019). The olive harvest is expen- 
sive in terms of wages and adequate labor supply has brought about many problems (Zipori et al., 2014). Fruit damage, damages related to the olive tree, quality reduction, human injuries, time consumption, and costly process in the traditional ways are problems existing in the harvesting process. Mechanized harvesting is done in many different types, such as the trunk and limb shakers. Because of device feature like power supplement implementation of this shakers are difficult (Çakmak et al., 2011). Although, the mechanized harvesting methods are very efficient but they have an high usage costs. Therefore, the best harvest system should be inexpensive and highly efficient.

Designing of shakers, harvesting efficiency analyzing and tree damage for olive fruits are the attractive topics in the mechanization field, so in this regards researchers studied the effect of shaking force and the amplitude of the shaking on the mechanized harvesting of olive. They showed that an increase in olive tree diameters trunks led to an increase in shaking force and a decrease in amplitude of the shaking. So, for mechanized harvesting in the big olive trees with big trunk diameters more power must be applied (Babanatsas et al., 2019). A comparative study was done to investigate the various ways of olive harvesting. Results show that harvesting through shaking the stem is the best way to remove the olive fruit from a tree (Yousefi et al., 2010). Five different olive harvesters were investigated. The flat type olive harvester has more vibration value index (Çakmak et al., 2011). The effect of two types of olive tree harvesting (Trunk Shaker and Mechanical Harvest Aid) on harvesting time were studied. Results show that harvesting the olive trees with mechanical harvest aid can save more time (Nayeri and Torkashvand, 2016). Results concerning the examination of harvesting type on harvesting efficiency show that with increasing the fruit removal force the harvesting efficiency was decreased (Zipori et al., 2014). A study on four types of olive harvester; plastic combs, small shakers, rotating combs, and vibrating combs were done. Researchers indicated that all types of harvesters except the small shaker improve the worker's productivity (Bentaher and Ben Rouina, 2002). Results of the study on a pneumatic harvester showed that manual harvesting and mechanical harvesting methods had a significant effect. The pneumatic comb machine had higher bruised fruit than the manual harvesting (Ahmad, 2018). With an increase in the operating velocity, the productivity harvesting and damage percentage increased and the $1250 \mathrm{rpm}$ operating velocity value could be a good alternative for harvesting (Mansour et al., 2018). Two methods of harvesting olive fruit, namely, mechanized harvesting with Pneumatic Harvester (PH) and Manual Harvesting ( $\mathrm{MH}$ ) were investigated, which indicated that due to the presence of the collector system, using mechanized harvesting can reduce the fruit damages (Plasquy et al., 2019). Mechanical canopy and trunk shaking were investigated in line with the harvesting mechanization of table olive orchards. Accumulating the trunk shaker and shaker combs can increase the bruise index of olive fruits. The lowest bruise index of olive fruits belongs to the manually-type harvest with a $0.5 \%$ value (SolaGuirado et al., 2020).

The designing and fabrication of olive fruit harvester have long since been the subject of many types of research. Applying some of these systems may exert large costs on farmers, and the efficiency of these machines requires significant economic costs that many producers cannot afford. For this large group of farmers, new models have recently been presented. Nevertheless, the use and utility of some of these machines still entail difficulties, such as the large weight, difficult access to the trunks, or handling the fruit boxes. In this study, results concerning the evaluation of a new design of portable pneumatic olive harvester with a fruit collector system are presented to fix some of the harvesting problems. The evaluation parameters of harvesting machine (such as: the harvesting efficiency, harvesting productivity, and olive tree damage) were compared both with the manual method and similar harvesting methods. Finally, the effect of fruit collector on fruit damage was investigated.

\section{Materials and Methods}

\section{Vegetal material}

Two different varieties ('Mari' and 'Yellow') of olive fruits were selected to evaluation that both of them are Iranian variety and commonly grown for oil and canned production. The first step in designing a new harvesting machine is cognition about crop characteristics such as detachment force from tree branches. For measuring fruit detachment force from tree branches, three tree of each verity were selected and ten olive fruits of each tree accidentally were selected. The force required to detach them was 
measured by a mechanical force gauge. The mechanical gauge of FG-5020 model was used and calibrated in the Precision Process Calibration Laboratory with the approval of No. 681 of the Standard Institute of Iran.

The fruit detachment force employed to determine the applied force on the pneumatic jack. So to determine this amount assuming that all of the jaw surface covered by the olive fruit and the detachment force in this situation was calculated.

Tests were conducted in the Ashrafieh gardens in Qazvin province in Iran and the fruit ripening index was $4.52 \%$. The age of olive trees was 20 years and the height of trees was up to $3.5 \mathrm{~m}$.

\section{Harvester machine design}

The pipe diameter is a very important factor for designing pneumatic systems. When the low pipe diameter was applied, the pressure dropped and the airflow velocity increased accordingly. In the case of water penetration into the pipe, the clogged pipes situation was expected to happen. Two conditions, namely, $5-8 \mathrm{~m} / \mathrm{s}$ and 0.5 bar were found to be appropriate for the airflow velocity and the pressure dropped.

The first step for jack design is to define the required pressure and velocity of air to detach the olives from the tree. Equation (1) shows the jack piston, which was used to calculate the air force.

$$
\mathrm{F}_{m}=P \times a
$$

After selecting jaws frequency and active volume of the piston, the cam length and Air Mass Flow (AMF) were calculated. The amount of AMF for jaw movement to open the jaw was calculated by equation (2), and in the closed cycle, equation (3) was used for the AMF. Finally, the total AMF to open and close the jaws was calculated by equation (4).

$$
\begin{gathered}
Q_{\text {ext }}=\pi \times\left(D^{2} / 4\right) \times \chi \times n \times\left(P_{1}-P_{0}\right) / P_{0} \\
Q_{\mathrm{ret}}=\pi \times\left[\left(D^{2}-\mathrm{d}^{2}\right) / 4\right] \times \chi \times n \times\left(P_{1}-P_{0}\right) / P_{0} \\
Q_{\mathrm{tot}}=\pi \times\left[\left(2 \mathrm{D}^{2}-\mathrm{d}^{2}\right) / 4\right] \times \chi \times n \times\left(P_{1}-P_{0}\right) / P_{0}
\end{gathered}
$$

Assuming that the total pneumatic energy was converted to the kinematic energy, the maximum velocity could be determined using Equation (5).

$$
E=1 / 2 m\left(v_{\max }\right)^{2}
$$

The total energy required was calculated by equa- tion (6).

$$
E=\left[\frac{1}{2} P \times \pi D^{2} \times m(0.5)^{2}\right] /(2 g \times 4)
$$

The total energy for opening the jaw was calculated by equation (7):

$$
E=5 \times 10^{-4} \times P\left(D^{2}-d^{2}\right)
$$

The determinations show that the detachment force of olive fruit from the tree and the pressure required for the pneumatic jack were $10 \mathrm{~N}$ and 7 bar, respectively. The machine had one handle and it was gripped by one operator's hand and a telescoping rod up to a maximum length of $3 \mathrm{~m}$. The harvesting mechanism had two jaws and each jaw contained 7 fingers that allowed for easy and deep access to all types of foliage without getting caught in the branches. 90 degrees was selected for the angle between two jaws based on the previous researches. The jaws had $18 \mathrm{~cm}$ length and the distance between them must be equal to the olive fruit width, so $1 \mathrm{~cm}$ distance was considered. We assume that in every impact of jaws, 23 olive fruits were detached from tree branches. So, the total force required for each impact was determined. The force related to the pneumatic cylinder was determined by equation (8).

$$
2 f_{d} \operatorname{Cos}(\theta / 2)=F
$$

The amount of force of each jaw for the olive fruit detached from the tree was $325.3 \mathrm{~N}$, and for calculating the piston diameters equation (9) was used.

$$
F=A \times P
$$

After determining the piston diameters, the length of the cam was calculated and the standard jack with these characters was selected.

The cylinder provides a closed system which assists the movement of the piston. For moving the piston across the cylinder in high frequency, valves must be used or the manual control applied. Because of the operation conditions, the pneumatic valve was selected to change the airflow direction. When the pneumatic valve was in position A, high air pressure pushed the piston to the right side (Fig. 1). By moving the piston to right, the airflow was transferred to the $C$ input of the pneumatic valve which changed the direction of airflow, resulting in the activation of the $B$ position of the pneumatic valve. When high-pres- 
sure air moves to the B output of the pneumatic valve, the piston moves to the left side, and air moves toward the $D$ input of the pneumatic valve, and such a cycle is replicated. After assembling the parts, the frequencies of these cycles were measured by an electronic eyes sensor. The frequency of the piston movement is $5.21 \mathrm{~Hz}$ in 7 bar air pressure. So, after defining design parameters, the mechanical value of No. G1/8" was selected. Other parts of the harvester such as the chain, cam, and pneumatic value along with the parts were designed.

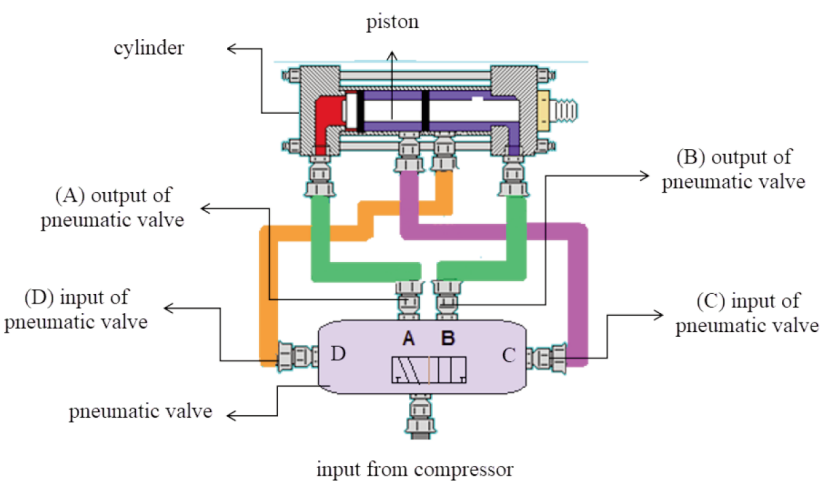

Fig. 1 - Schematic of the piston, cylinder, valve, and connector pipes

Figure 2 shows the details of NPH, including harvester jaws, cylinder and pneumatic valve, power transmission, and telescoping rod.

The common properties of the collector system for olive fruit are shown in Table 1. By applying this system, the olive fruits falling from the tree were collected into a box. The driving power of the collector system are provided by labor.

It is possible to conclude from figure 3 that the collector system is ready to collect the fruits in the box. The collector system includes the wheels, steering wheel, bendable bars, wire for hold cover, polyester cover, trunk holder, position for boxes, and outlet, all of which are assembled on chassis.

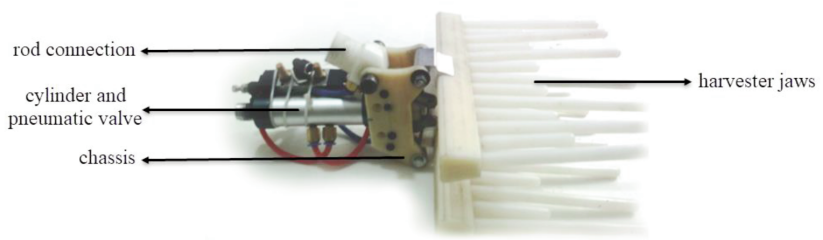

Fig. 2 - The different parts of the new pneumatic harvester.
Table 1 - Collector system properties

\begin{tabular}{lc}
\hline Parameters & Value \\
\hline Chasses length & $140 \mathrm{~cm}$ \\
Chasses width & $95 \mathrm{~cm}$ \\
Trunk holder height & $60 \mathrm{~cm}$ \\
Trunk diameter & up to $40 \mathrm{~cm}$ \\
Cover diameter & $300 \mathrm{~cm}$ \\
\hline
\end{tabular}

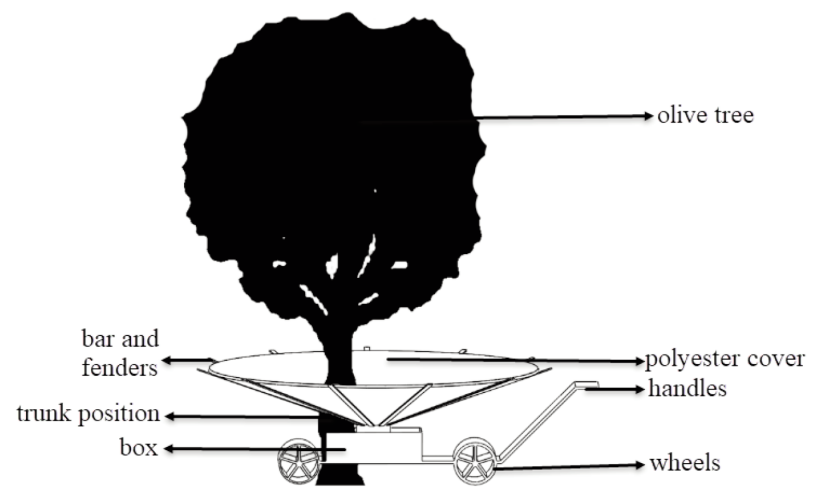

Fig. 3 - Collector system parts.

\section{Statistical design}

The variance analysis was done in randomized complete block design with three replicate and the statistical computations as well as analyzing the data were performed by the MSTAT-C software. Duncan's multi-scope test was used for comparison of the means.

The performance of the developed harvest machine was measured by the Harvesting Productivity (HP), harvesting efficiency $(\mathrm{HE})$, and leaves downfall percent (LD). The performance of the developed collector system was measured by the olive fruit damage (FD). For measuring the harvesting productivity of olive fruit harvester, the total mass of detachment fruits was recorded using the machine. The total harvesting time includes selecting, detaching fruit, and the time required for moving machine between olive trees inside the field. The productivity of the operated harvester was calculated using equation (10) (Polat et al., 2007):

$$
H P=k_{1} / T
$$

Harvesting efficiency was calculated by equation (11) (Srivastava et al., 2006).

$$
H E=\left[k_{1} /\left(\mathrm{K}_{2}+\mathrm{K}_{1}\right)\right] \times 100
$$


The percent of olive leaves downfall is defined as the percent of branches and leaves fall down by the harvester and was calculated by equation (12):

$$
T D=M_{b l} / M_{t b l} \times 100
$$

The total weight of branches and leaves of the olive trees previously measured. Some trees that had to be removed were collected and weighed separately, finally the means weight of the branches and leaves of three trees were used in the equation (12).

Fruit damage includes the visual inspection and the fruit appearing broken to the naked eye. Fruit damage was calculated by equation (13).

$$
F D=M_{d} / M_{t} \times 100
$$

The main criteria for designing the New Pneumatic Harvester (NPH) were as follows: easy design, simple to use, low weight, high productivity, less fruit damage, and low operating costs. The main novelty of this type of harvester is low operating costs and use in gardens far from the energy networks. A double-sided jack was used to provide jaw movement so, the required airflow rate, pressure drop, airflow control valve, and jack size must be defined.

To show the advantages and disadvantages of the present device with existing devices, the results of the evolution of the NPH compared with a Pneumatic Harvester $(\mathrm{PH})$ that the features of the $\mathrm{PH}$ are shown in Table 2.

Table 2 - PH technical features

\begin{tabular}{ccc}
\hline Number & Feature & Amount \\
\hline 1 & model & Campagnola srl \\
2 & weight & $1 \mathrm{~kg}$ \\
3 & length & $1.8-3 \mathrm{~m}$ \\
4 & Max pressure & $7 \mathrm{bar}$ \\
\hline
\end{tabular}

\section{Results and Discussion}

\section{Results of the harvesting tests}

Harvesting productivity was calculated among 3 types of different harvesters' system ( $\mathrm{MH}, \mathrm{PH}$ and $\mathrm{NPH}$ ), using the equation number " 10 " (Table 3 ). Results showed that the three harvesters have a significant difference at $5 \%$ levels of probability. Due to different treatments, the means were compared and the NPH was found to have more HP placed in a group (a) with an amount of $29.47 \mathrm{~kg} / \mathrm{h}$. The $\mathrm{PH}$ was placed in a group (b) with an amount of $21.33 \mathrm{~kg} / \mathrm{h}$ and the $\mathrm{MH}$ was placed in a group (c) with an amount of $9.37 \mathrm{~kg} / \mathrm{h}$.

Table 3 - Result of variance analysis velocity $\left(\mathrm{m} \mathrm{s}^{-1}\right)$ for harvesting productivity

\begin{tabular}{lcccc}
\hline Parameters & df & $\begin{array}{c}\text { Sum of } \\
\text { squares }\end{array}$ & $\begin{array}{c}\text { Means of } \\
\text { squares }\end{array}$ & $\mathrm{F}$ \\
\hline Block & 2 & 34.925 & 17.462 & $1.6126^{*}$ \\
Harvest method & 2 & 283.554 & 141.777 & $13.093^{*}$ \\
total & 4 & 43.314 & 10.828 & \\
CV & $25 \%$ & & & \\
\hline
\end{tabular}

* = significant at $5 \%$ of probability.

$* *$ = significant at $1 \%$ of probability.

NS = not significant.

Figure 4 shows the HP means for three harvest methods. Due to the special properties of NPH such as the power of vibration, frequency, and shape of a bar, the HP of this machine was more when compared to two other methods of harvesting. Kermani (2016) indicated that the mounted branches shaker machine has $130.72 \mathrm{~kg} / \mathrm{h}$ of HP, but it fails to be used in traditional gardens. This type of harvester needs a tractor to perform, which is not feasible for small gardens (Kermani, 2016).

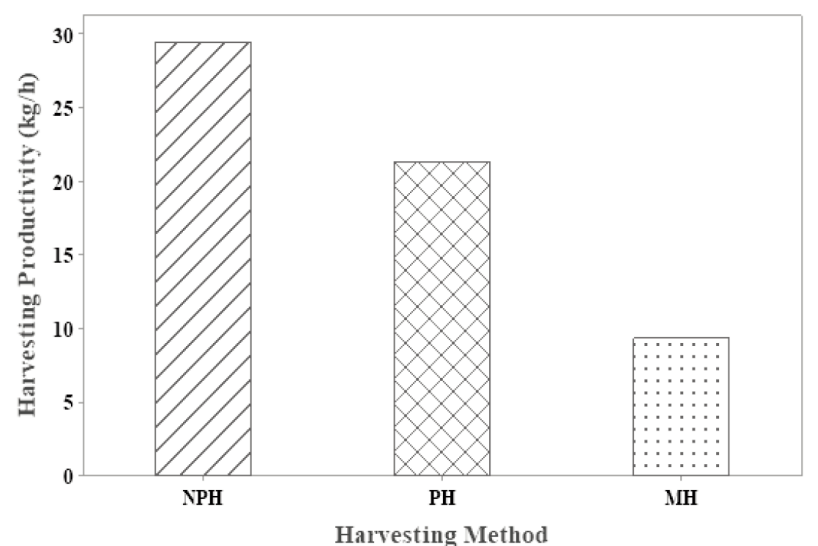

Fig. 4 - Harvesting productivy means for three harvesting methods. $\mathrm{NPH}=$ New pneumatic harvester; $\mathrm{PH}=$ pneumatic harvester; $\mathrm{MH}=$ manual harvesting.

Table 4 shows the results of variance analysis related to the difference between two types of harvesting machine concerning the Harvesting Efficiency $(\mathrm{HE})$. The analysis shows that the effect of machine type on HE is significant at $1 \%$ probability. The pneumatic harvester can detach $86 \%$ of olives from the tree, but NPH shares $92 \%$ of HE. Because of the availability of all olives on the tree, the HE of this method 
is considered as $100 \%$ for labor in the case of manual harvest (Fig. 5).

It is very important to understand how to place the harvesting head on the telescoping rod. The angle between the harvester head and telescoping rod in the NPH is fixed and the jaws move between 123 to 213 degrees, and such a property differs from the $\mathrm{PH}$. The other important difference resulting in increased $\mathrm{HE}$ is the jaws speed, where they move quicker in NPH compared to the $\mathrm{PH}$. Some places of olive fruits on the tree are not available for NPH and $\mathrm{PH}$. The harvester rod plays the important role in the $\mathrm{HE}$. Whatever the harvesters rod has high maneuverability the more olive fruits can detected and the HE increased. Kermani (2016) showed that the olive tree branches shaker machine has $84.51 \% \mathrm{HE}$, but compared to other machines, the leaves downfall percent in this harvesting method is high (Kermani, 2016).

Equation 12 was used to determine Leaves downfall percent (LD). After harvesting, all the branches and leaves were collected and weighted. By increasing in branches and leaves that fall from the tree the

Table 4 - Result of variance analysis of for harvesting efficiency

\begin{tabular}{lcccc}
\hline Parameters & df & $\begin{array}{c}\text { Sum of } \\
\text { squares }\end{array}$ & $\begin{array}{c}\text { Means of } \\
\text { squares }\end{array}$ & $\mathrm{F}$ \\
\hline Between data & 1 & 717.883 & 717.838 & $118.644^{* *}$ \\
Inside data & 4 & 24.203 & 6.05 & \\
CV & $3.25 \%$ & & & \\
\hline
\end{tabular}

* = significant at $5 \%$ of probability.

$* *=$ significant at $1 \%$ of probability.

NS = not significant.

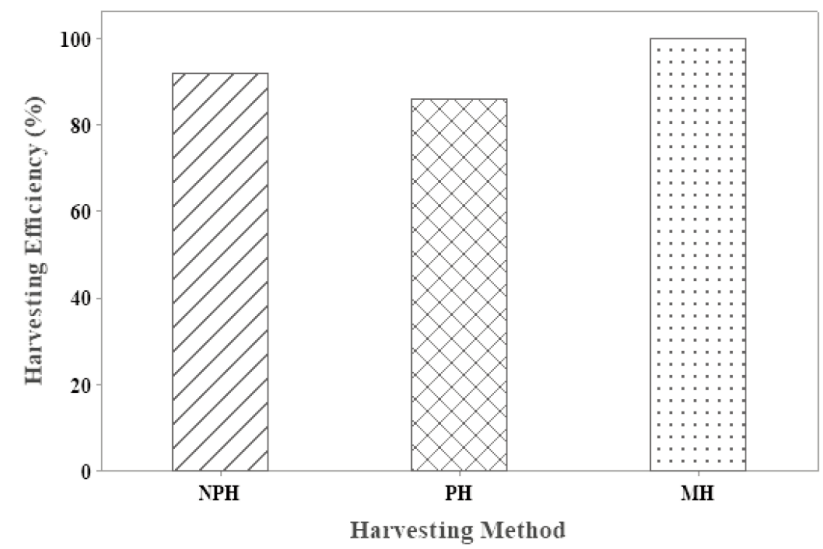

Fig. 5 - Harvesting efficiency means for three harvesting methods. $\mathrm{NPH}=$ New pneumatic harvester; $\mathrm{PH}=$ pneumatic harvester; $\mathrm{MH}=$ manual harvesting.
LD was increased. Table 5 shows the variance analysis among the three harvesting methods and olives types. The effect of variety (type) on LD was not significant, but harvesting methods have a significant effect on LD. Figure 6 shows the LD for three harvesting methods; NPH has more LD than the two other harvesting methods. The speed of jaws in the $\mathrm{PH}$ is 1080-1150 rpm, while in the NPH the minimum speed of jaws is $1290 \mathrm{rpm}$. This difference in jaws speed led to an increase in the leaves' downfall percent.

Table 5 - Result of variance analysis for leaf downfall

\begin{tabular}{lcccc}
\hline Parameters & df & $\begin{array}{c}\text { Sum of } \\
\text { squares }\end{array}$ & $\begin{array}{c}\text { Means of } \\
\text { squares }\end{array}$ & $F$ \\
\hline Block & 2 & 0.286 & 0.143 & 42503 NS \\
Harvest method & 2 & 1.006 & 0.503 & $14.934^{*}$ \\
total & 4 & 0.135 & 0.034 & \\
CV & $8.93 \%$ & & & \\
\hline
\end{tabular}

* = significant at $5 \%$ of probability.

$* *$ significant at $1 \%$ of probability.

NS $=$ not significant.

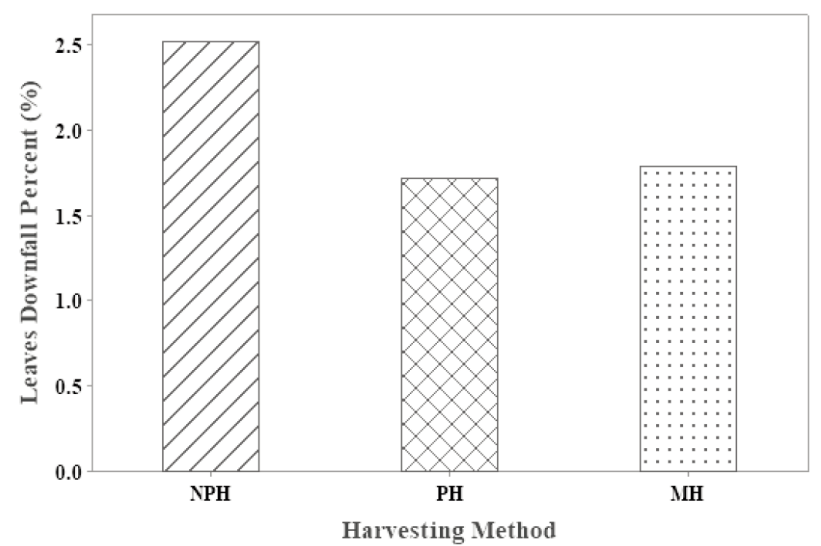

Fig. 6 - Leaf downfall (\%) means for three harvesting methods. $\mathrm{NPH}=$ New pneumatic harvester; $\mathrm{PH}=$ pneumatic harvester; $\mathrm{MH}=$ manual harvesting.

Comparison of the means of harvesting method shows that the NPH with an amount of $2.52 \%$ LD has the highest detachment of leaves from the tree. The $\mathrm{PH}$ and $\mathrm{MH}$ were not significantly different, and they were placed in a group (b). The electrical rotation bar in Kermani's (2016) research has the highest LD with a $2.20 \%$ damage (Kermani, 2016). Due to the problems with the head location on the handle in the $\mathrm{NPH}$, the amount of LD was increased, however, such a problem can be surmounted. 
Product quality results with the use of the collector system

Olive fruits fall on the ground after harvesting and get damaged as a result of this matter. To prevent the olive fruits from damage, a collector system gathering the fruits into the box was designed and manufactured. For evaluating the collector system, two types of olive trees were harvested with the new pneumatic harvester, and the percent of damaged and undamaged olive fruits were investigated. Table 6 shows the damaged and undamaged olive fruit in the NPH with the collector systems and manual harvest without the collector system.

Results show that the use of a collector system can decrease the fruit damage (FD) from $60.80 \%$ to $25.12 \%$ in the 'Mari' variety. Similar results were achieved for the 'Yellow' variety. Table 6 shows the damaged and undamaged olive fruit for the harvesting of 'Yellow' olive fruit variety in the two harvesting methods. Figure 7 shows the injured, bruised, and uninjured olive fruit percent in fourteen measured samples for the manual harvest. Due to the difference in the weight of olive fruits, the percent of each group shown was based on the number and weight of olive fruits. In the manual harvest, a large portion of the fruits of the olive falls on the ground, then picked up and collected into the box. This process led to the bruising of more than half of the olive fruits. Table 7 shows the means, standard deviation, average deviation, variance, minimum and maximum of weight along with the number of injured, bruised, and uninjured olive fruits in $\mathrm{MH}$ and $\mathrm{NPH}$. Results show that after harvesting the fruits of the olive in the manually harvest method, $45.29 \%$ of olives fruits

Table 6 - Damaged and undamaged fruits in two types of harvesting method in Mari and Yellow variety

\begin{tabular}{lccccc}
\hline & \multicolumn{2}{c}{ Manual harvesting } & & \multicolumn{2}{c}{ New pneumatic harvester } \\
\cline { 2 - 3 } \cline { 5 - 6 } Cultivar & $\begin{array}{c}\text { Undamaged fruit } \\
\text { Mari }\end{array}$ & $\begin{array}{c}\text { Damaged fruit } \\
(\%)\end{array}$ & & $\begin{array}{c}\text { Undamaged fruit } \\
(\%)\end{array}$ & $\begin{array}{c}\text { Damaged fruit } \\
(\%)\end{array}$ \\
\hline Yellow & 39.2 & 60.8 & & 74.88 & 25.12 \\
\end{tabular}

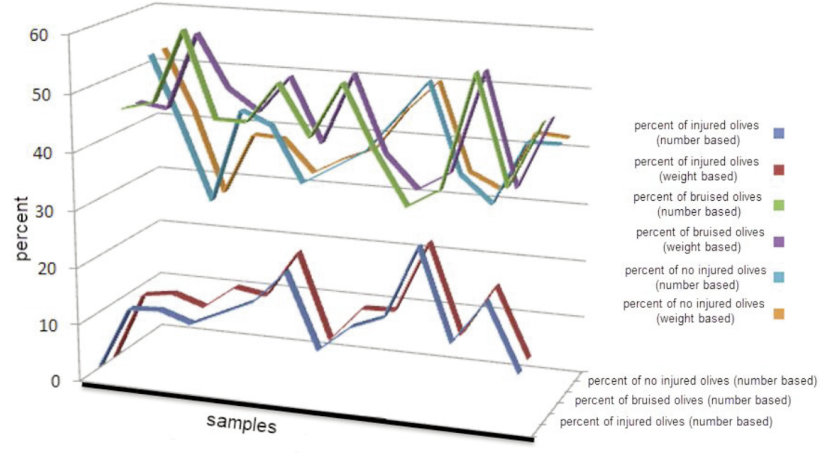

Fig. 7 - Illustration of the injured, bruised, and no injured olive fruit in the manually harvest. were bruised. Bruising occurred on the skin of the olive fruits as a result of fruit hitting on the soil. Also, the injuring situation occurred when fruits were hit by sharp branches or stones.

The percent of injured, bruised, and uninjured olive fruits for NPH based on the number and weight is shown in figure 8 . The results improved significantly. Most parts of the olives fruit had no injury in the harvesting process. Olive fruits that were detached from the tree fall in the collector systems and avoid contact with the stones or the soil/ground. Table 7 also shows the results of measuring related to the injured olive fruit parameters. The means of unin-

Table 7 - Results of measuring the injured parameters for the olive fruits in manual harvesting and new pneumatic harvester

\begin{tabular}{|c|c|c|c|c|c|c|}
\hline Harvesting type & $\begin{array}{c}\text { Number of } \\
\text { injured } \\
\text { olives }\end{array}$ & $\begin{array}{l}\text { Weight of } \\
\text { injured } \\
\text { olives }\end{array}$ & $\begin{array}{c}\text { Number of } \\
\text { bruised } \\
\text { olives }\end{array}$ & $\begin{array}{c}\text { Weight of } \\
\text { bruised } \\
\text { olives }\end{array}$ & $\begin{array}{c}\text { Number of no } \\
\text { injured } \\
\text { olives }\end{array}$ & $\begin{array}{c}\text { Weight of } \\
\text { no injured } \\
\text { olives }\end{array}$ \\
\hline Manual harvesting & $14.87 \pm 1.70 *$ & $15.51 \pm 1.71$ & $45.42 \pm 2.04$ & $45.29 \pm 1.98$ & $39.71 \pm 1.95$ & $39.20 \pm 1.87$ \\
\hline New pneumatic harvester & $7.98 \pm 1.14$ & $8.33 \pm 1.36$ & $15.98 \pm 2.75$ & $16.79 \pm 2.79$ & $76.02 \pm 2.96$ & $74.88 \pm 2.98$ \\
\hline
\end{tabular}

* Means \pm standard deviation. 
jured olive fruits in the NPH increased from $39.71 \%$ to $76.02 \%$. This means that the NPH was able to save almost half of the olive fruits. The jaws hitting olive fruits and detached fruits from brunches after that fruits falling from the tree and collide with the branch and trunk of the tree. This process caused almost $24 \%$ damage to the olive fruits. $16 \%$ of the olive fruits in the harvesting process were bruised and the rest of the damaged fruits got the ruptured skin, which was then classified as the injured fruits.

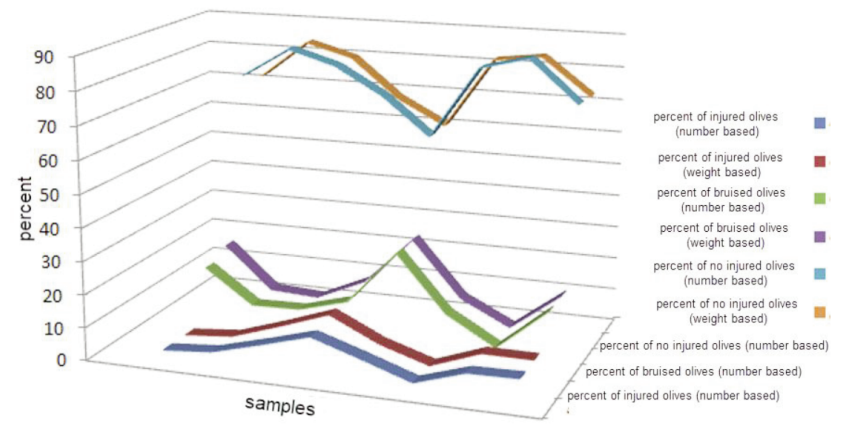

Fig. 8 - Schema of the injured, bruised, and no injured olive fruit in harvesting with new pneumatic harvester.

\section{Conclusions}

Harvesting is one of the important steps in the olive farming and the device that used also strongly effected on the quality of the harvesting. In this study, tried to investigate the New Pneumatic Harvester performance to show its advantage in compared with other pneumatic harvesters that exist in the market. When considering the fruit ripening index of $4.52 \%$, one can say only $8 \%$ of olive fruits remained on the trees. On the other hand, the amount of HP was $29.47 \mathrm{~kg} / \mathrm{h}$. This result shows that NPH can detach $92 \%$ of olives on the tree in a short time. In the case of the traditional and small gardens, this machine is very practical because it can work effectively in the garden in different situations. The collector system saves more time and prevents olive fruit from damage and can be easily used for every harvesting method.

\section{Acknowledgements}

This research was supported by Iran National
Science Foundation (INSF) with 92032254 number. We thank our colleagues from INSF who provided insight and expertise that greatly assisted the research.

\section{References}

AHMAD R.L., 2018 - Efficiency of mechanical tools for olive harvest and effect on fruit quality. - Acta Horticulturae, 1199: 315-319.

BABANATSAS T., GLAVAN D.O., BABANATIS MERCE R.M., GLAVAN A.I., 2019 - Study of forces influencing the shaking parameters in mechanized/robot-assisted harvesting of olives. - MATEC Web of Conferences, vol. 290, pp. 03001.

BARBERA A.C., MAUCIERI C., CAVALLARO V., IOPPOLO A., SPAGNA G., 2013 - Effects of spreading olive mill wastewater on soil properties and crops, a review. - Agric. Wat. Manag., 119: 43-53.

BENTAHER H., BEN ROUINA B., 2002 - Mechanical harvesting of 'chemlali de sfax' olive-trees. - Acta Horticulturae, 586: 365-368.

ÇAKMAK B., SARAÇOĜLU T., ALAYUNT F.N., ÖZARSLAN C., 2011 - Vibration and noise characteristics of flap type olive harvesters. - Appl. Ergonomics, 42(3): 397-402.

FIORINO P., MARONE E., OTTANELLI A., 2010 - Mechanical harvesting, productivity and superintensive planting systems in olive groves. - Adv. Hort. Sci., 24(1): 91-94.

KERMANI A., 2016 - Comparison of four harvesting machines for harvesting of oil olive. - J. Engineering Res. Agric. Mechan. Systems, 16(65): 1-18.

LUPI F.R., GABRIELE D., FACCIOLO D., BALDINO N., SETA L., DE CINDIO B., 2012 - Effect of organogelator and fat source on rheological properties of olive oil-based organogels. - Food Res. Inter., 46(1): 177-184.

MANSOUR H.A., ELMESIRY T.A., ABDELHADY A.A., 2018 The effect of operating speed and olive varieties harvested by hand-held machine on productivity and damage percentage. - World Wide J. Multidisc. Res. Develop., 4(2): 355-360.

NAYERI F., TORKASHVAND A.M., 2016 - Techno-economic efficiency of trunk and mechanical harvest aid shakers for harvesting olive fruits in Guilan Province, Iran. Inter. J. Agric. Manag. Devel. (IJAMAD), 6(3): 273-280.

OTTANELLI A., MARONE E., FIORINO P., 2019 - A new device to improve the mechanical winter pruning in olive trees hedgerows. - Adv. Hort. Sci., 33(1): 113-122.

PLASQUY E., SOLA-GUIRALDO R.R., FLORIDO C., GARCÍA J.M., BLANCO-ROLDÁN G., 2019 - Evaluation of a manual olive fruit harvester for small producers. - Res. Agric. Engineering, 65(4): 105-111.

POLAT R., GEZER I., GUNER M., DURSUN E., ERDOGAN D., BILIM H.C., 2007 - Mechanical harvesting of pistachio nuts. - J. Food Engineering, 79(4): 1131-1135. 
SOLA-GUIRADO R.R., CASTILLO-RUIZ F.J., BLANCO-ROLDAN G.L., 2020 - Mechanical canopy and trunk shaking for the harvesting mechanization of table olive orchards. Revista Facultad Ciencias Agrarias, UNCuyo, 52(2): 124139.

SRIVASTAVA A.K., GOERING C.E., ROHRBACH R.P., BUCKMASTER D.R., 2006 - Engineering Principles of Agricultural Machines. - Amer.Soc. Agric. Biol.
Engineers, Second Edition, St. Joseph, MI, USA.

YOUSEFI Z., ALMASSI M., ZEINANLOO A.A., MOGHADASI R., KHORSHIDI M.B., 2010 - A comparative study of olive removal techniques and their effects on harvest productivity. - J. Food, Agric. Environ., 8(1): 240-243.

ZIPORI I., DAG A., TUGENDHAFT Y., BIRGER R., 2014 Mechanical harvesting of table olives: Harvest efficiency and fruit quality. - HortSci., 49(1): 55-58. 
